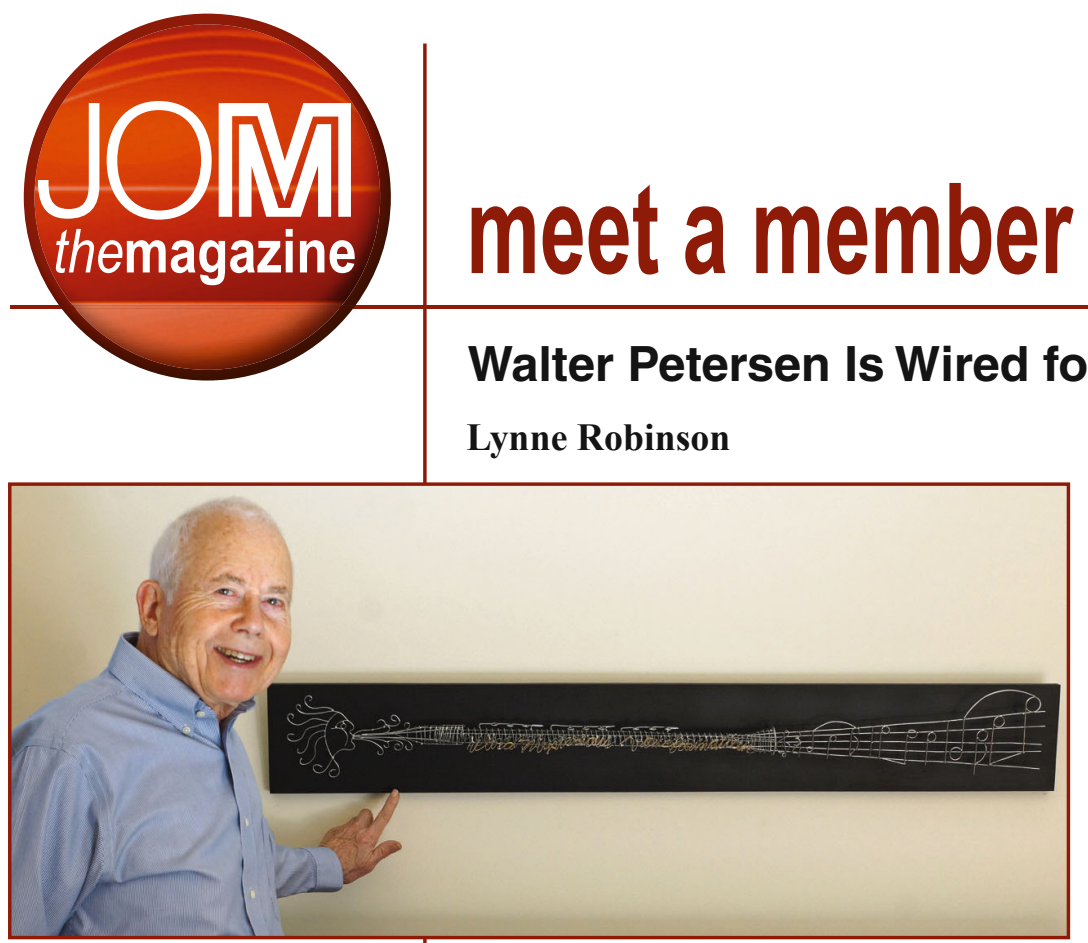

Walter Petersen shows off Ultra Mysterious Transformation, his wire sculpture that presents wind being blown into a clarinet, with the first three bars of Mozart's Clarinet Concerto exiting the bell. Made of galvanized steel and brass wires, it won Best of Show in 2014 in an art show themed "Entrances and Exits."
Galvanized steel wire is generally relegated to such utilitarian uses as fencing and binding material. In Walter A. Petersen's hands, it transforms into intricate floral designs, familiar faces, and even the entire state of Florida.

Armed with a soldering iron and an assortment of pliers, Petersen bends wire to his will and imagination to create unique works of art that have won numerous awards in juried shows sponsored by the Island Art Association, Fernandina Beach, Florida. Petersen joined the association in 2006 to exhibit his photography_another artistic hobby that he has pursued in his retirement. He had been experimenting with sculpted wire pieces for a few years and decided to enter one in a 2010 competition

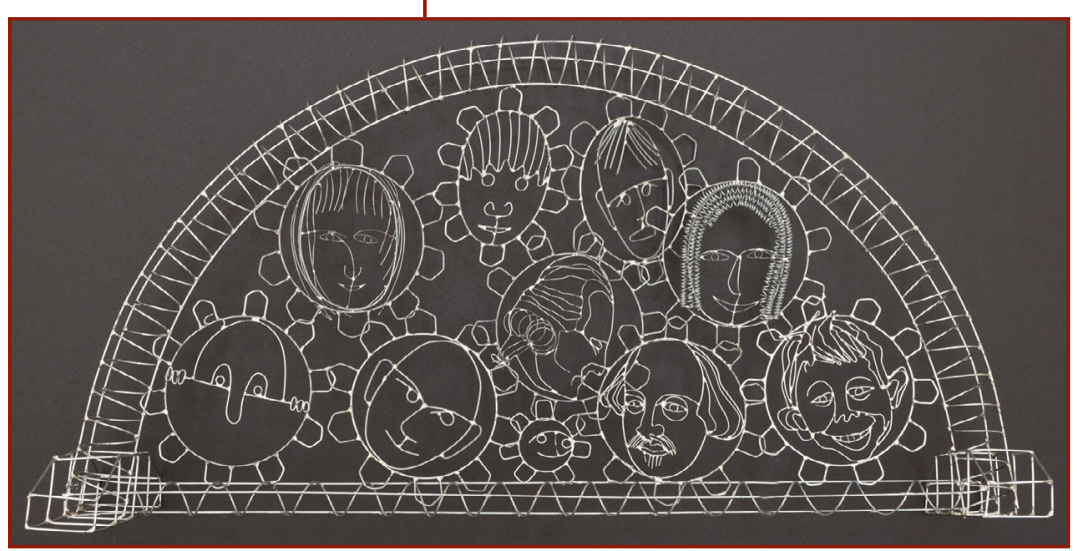

Stage uses curved and straight versions of the spiral beam that Petersen devised in the course of developing his artwork. It won third place in a juried show in 2014.

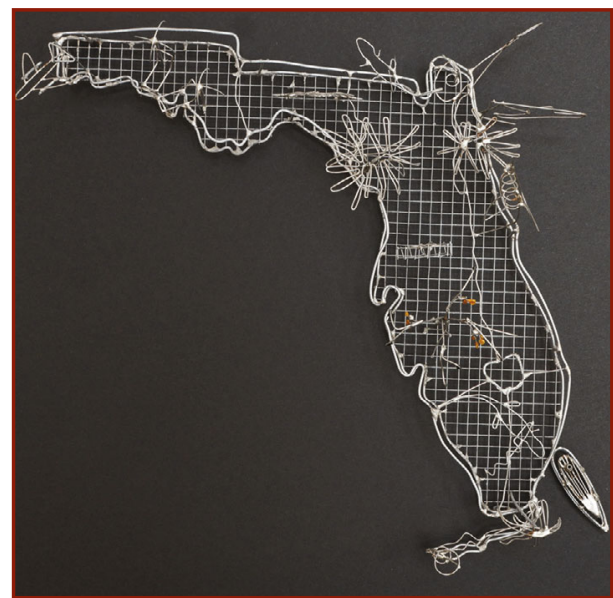

Petersen managed to incorporate a number of important Florida landmarks in this wire homage to his home state.

to see what feedback he would receive. The piece won first place and was subsequently purchased by a private collector. "I realized I was on to something, spiking my interest in this area of art," Petersen said.

While various approaches to wire sculpture have been in existence for years, Petersen discovered that he had to develop his own version of the art form to

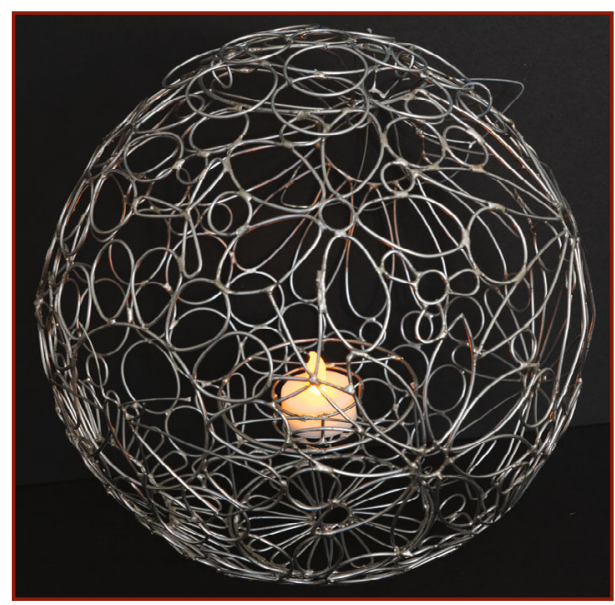

Petersen constructed Jardin Sphériques on a polystyrene foam ball. After completing the wire sculpture, he used acetone to melt away the polystyrene and leave the sculpted shape behind, in a technique similar to the lost foam casting process. 
realize his particular vision for his pieces. Along the way, he has created several new techniques and is particularly proud of a spiral beam that he invented to support the components of a large mobile that he created. "This special form of truss appears to be novel and I have used it in several of my sculptures," he said.

Informing Petersen's art is the knowledge he gained in developing advanced and specialty welding wires with Inco (now Vale) and later with Polymet Corporation. "I've never taken a workshop or class to develop my art. I just use my life experiences as a welder, trained in the U.S. Army, as well as a researcher in welding and wire manufacture," he said. A professional member of TMS since 1980, Petersen can actually trace back his involvement with the society to when he served as student chapter president at the Polytechnic Institute of Brooklyn, where he earned both his undergraduate and master's degrees in metallurgical engineering in 1956 and 1963, respectively.

The issues that Petersen must address at times in creating art are not unlike those he managed as an engineer. "The challenge is the conception followed by the reduction to practice. It is the two- or three- dimensional spatial relationships that must be worked out prior to beginning the piece," he explained. "These are followed by execution of the piece with the hundreds of decisions required for completion. I learn at least one new technique from each piece."

Petersen is often inspired to create a piece supporting the theme of an art competition, but he also frequently starts a project "on just a whim or an idea that I can rapidly translate into reality. If the prototype holds promise, I pursue it. Otherwise, I find some

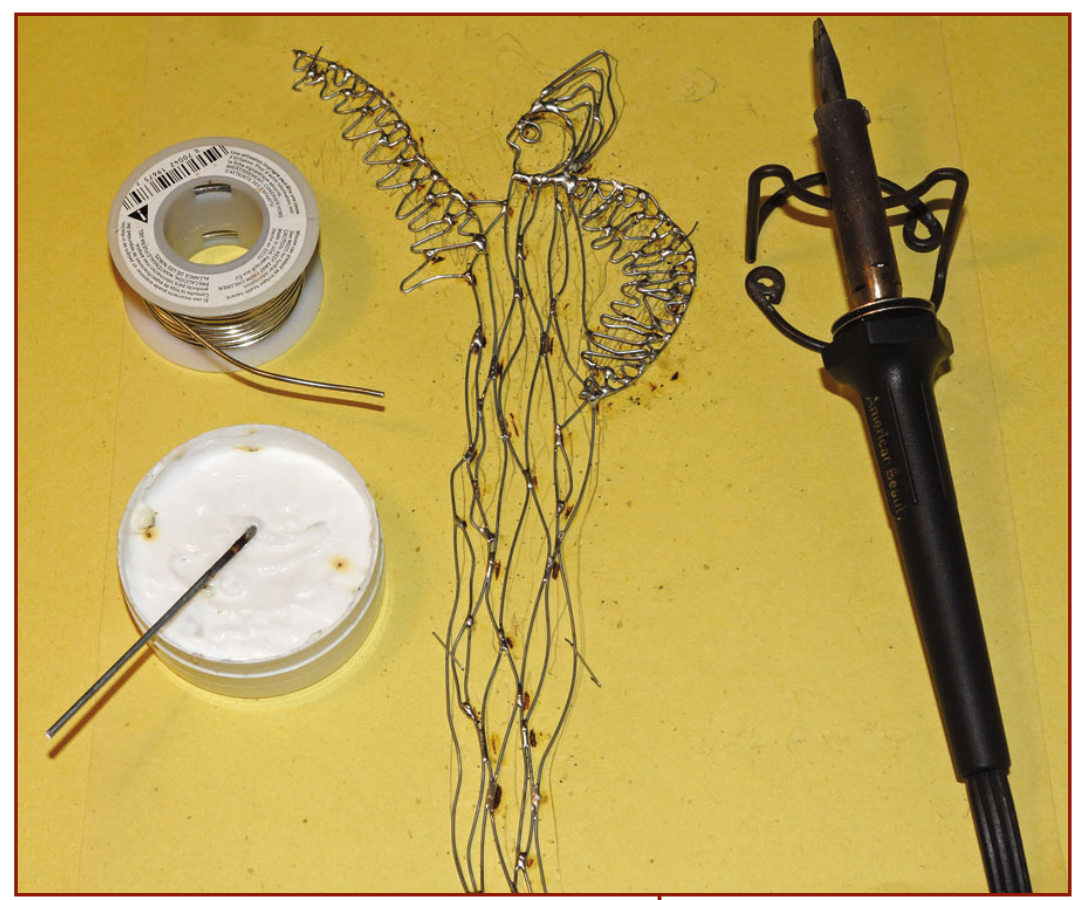

other worthy project to work on," he said. And, while it is obvious that Petersen has a wealth of natural artistic ability, he notes that he didn't really tap these talents until a little later in life. "I was not overly involved with art as a child," he recalls. "I was more into taking things apart and figuring out how they worked."

Petersen is always looking to push his work in different directions with his distinctive blend of artistic and engineering techniques. His current exploration is adding color to his sculptures with thin plastic films, with the intent that these newest creations will continue his winning ways in local art shows. "Being awarded a prize by a judge in a competition with many respected artists helps one's pride," he said. "Being able to sell the art to the public verifies one's abilities."
A work setup for one of Petersen's pieces. "I generally start with a sketch and then prepare a working drawing for each piece that is placed on a cardboard working surface," he explained. Petersen bends the wires to conform to the drawing and staples them in place before soldering the components together. The completed pieces are abrasively cleaned and washed, followed by treatment with an oxidationand corrosion-resistant coating.

\section{member news}

\section{Alton Romig Named NAE Executive Officer}

Alton D. Romig, 2005 TMS Fellow, joined the leadership team of the U.S. National Academy of Engineering (NAE) as executive officer in March. The NAE executive officer serves as the academy's chief operating officer. Romig has been an NAE member since 2003.

Romig had previously served in several positions at the Lockheed Martin Aeronautics Company, including vice president and general manager of the Skunk Works. Prior to this, he worked for 30 years at Sandia National Laboratories, ultimately rising to executive vice president, deputy laboratories director, and chief operating officer.

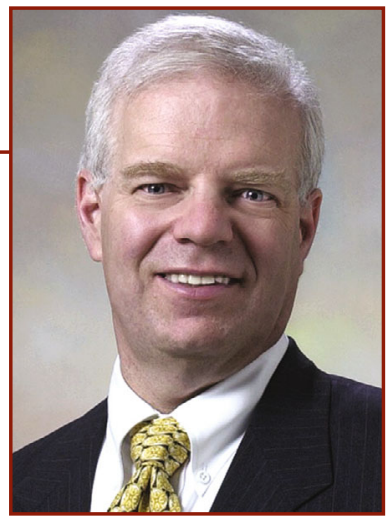

Alton D. Romig 